\title{
LEADER 5: prevalence and cardiometabolic impact of obesity in cardiovascular high-risk patients with type 2 diabetes mellitus: baseline global data from the LEADER trial
}

\author{
L. Masmiquel ${ }^{\text {* }}$, L. A. Leiter ${ }^{2}$, J. Vidal ${ }^{3}$, S. Bain ${ }^{4}$, J. Petrie ${ }^{5}$, E. Franek ${ }^{6}$, I. Raz ${ }^{7}$, A. Comlekci ${ }^{8}$, S. Jacob ${ }^{9}$, L. van Gaal ${ }^{10}$,
} F. M. M. Baeres ${ }^{11}$, S. P. Marso ${ }^{12}$, M. Eriksson ${ }^{13}$ and on behalf of the LEADER investigators

\begin{abstract}
Background: Epidemiological data on obesity are needed, particularly in patients with type 2 diabetes mellitus (T2DM) and high cardiovascular (CV) risk. We used the baseline data of liraglutide effect and action in diabetes: evaluation of CV outcome results - A long term Evaluation (LEADER) (a clinical trial to assess the CV safety of liraglutide) to investigate: (i) prevalence of overweight and obesity; (ii) relationship of the major cardiometabolic risk factors with anthropometric measures of adiposity [body mass index (BMI) and waist circumference (WC)]; and (iii) cardiometabolic treatment intensity in relation to BMI and WC.
\end{abstract}

Methods: LEADER enrolled two distinct populations of high-risk patients with T2DM in 32 countries: (1) aged $\geq 50$ years with prior CV disease; ( 2 ) aged $\geq 60$ years with one or more CV risk factors. Associations of metabolic variables, demographic variables and treatment intensity with anthropometric measurements (BMI and WC) were explored using regression models (ClinicalTrials.gov identifier: NCT01179048).

Results: Mean BMI was $32.5 \pm 6.3 \mathrm{~kg} / \mathrm{m}^{2}$ and only $9.1 \%$ had BMI $<25 \mathrm{~kg} / \mathrm{m}^{2}$. The prevalence of healthy WC was also extremely low (6.4\% according to International Joint Interim Statement for the Harmonization of the Metabolic Syndrome criteria). Obesity was associated with being younger, female, previous smoker, Caucasian, American, with shorter diabetes duration, uncontrolled blood pressure (BP), antihypertensive agents, insulin plus oral antihyperglycaemic treatment, higher levels of triglycerides and lower levels of high-density lipoprotein cholesterol.

Conclusions: Overweight and obesity are prevalent in high CV risk patients with T2DM. BMI and WC are related to the major cardiometabolic risk factors. Furthermore, treatment intensity, such as insulin, statins or oral antihypertensive drugs, is higher in those who are overweight or obese; while BP and lipid control in these patients are remarkably suboptimal. LEADER confers a unique opportunity to explore the longitudinal effect of weight on CV risk factors and hard endpoints.

Keywords: Liraglutide, Cardiovascular, Type 2 diabetes, LEADER, Cardiometabolic, Obesity, Overweight

\footnotetext{
*Correspondence: Imasmiquel@gmail.com

${ }^{1}$ Endocrinology and Nutrition Department, Hospital Son Llàtzer,

University Institute of Health Science Research (IUNICS-IdISPa), Universitat

de les Illes Balears, Palma, Majorca, Spain

Full list of author information is available at the end of the article
} 


\section{Background}

The association between different anthropometric measures of adiposity and cardiovascular (CV) risk in patients with established diabetes and high CV risk has not been well studied [1, 2]. Several longitudinal cohort studies have shown that patients with coronary artery disease and type 2 diabetes mellitus (T2DM) have lower mortality with a higher body mass index (BMI), suggesting that an "obesity paradox" exists [3]. Although lower muscle mass in patients with T2DM could be a plausible biological explanation for this [4], several confounding factors are likely to play a role in this apparent paradox. For example, BMI alone is recognised to be an imperfect measurement of the type of adiposity. Furthermore, some imbalance could be evident in other key parameters, including age, lipid levels, degree of metabolic control, $\mathrm{CV}$ risk factors and treatment intensity $[5,6]$. Therefore, additional data on the associations of these parameters are needed, especially in high CV risk patients with T2DM.

The LEADER (liraglutide effect and action in diabetes: evaluation of $\mathrm{CV}$ outcome results) trial is designed to assess formally the CV safety of liraglutide in patients with T2DM aged $\geq 50$ years with history of, or at high risk for CV events [7]. We used the cross-sectional baseline data from LEADER to investigate (i) the prevalence of overweight and obesity; (ii) the interplay among the major cardiometabolic risk factors and two anthropometric measures of adiposity [BMI and waist circumference (WC)]; and (iii) the treatment of cardiometabolic risk factors in relation to BMI and WC categories. Furthermore, because race and ethnicity significantly affect the associations between anthropometric indices and CV risk factors [8-10], we also investigated the influence of these characteristics.

\section{Methods}

LEADER is a phase $3 \mathrm{~B}$, multicentre, international, randomised, double-blind, placebo-controlled clinical trial with long-term follow-up designed to assess the $\mathrm{CV}$ safety of liraglutide up to $1.8 \mathrm{mg}$ daily, a glucagon-like peptide-1 receptor agonist (GLP-1RA) approved for treatment of patients with T2DM. A detailed description of the study design and baseline characteristics of the study population has previously been published [7]. Briefly, the trial enrolled a CV high-risk population of patients with T2DM at 410 sites in 32 countries who fit into one of the following categories: i) patients $>50$ years of age and concomitant CV disease (CVD), cerebrovascular disease, peripheral vascular disease, chronic renal failure, or chronic heart failure; ii) patients $>60$ years of age and one or more of the following CV risk factors: microalbuminuria or proteinuria, hypertension and left ventricular hypertrophy by electrocardiogram or imaging, left ventricular dysfunction by imaging, or ankle-brachial index of $<0.9$.

Physical exploration and anthropometric measurements were carried out according to the protocol by the investigators with the subject barefoot and wearing light clothes. BMI was the ratio of weight $(\mathrm{kg})$ divided by squared height $\left(\mathrm{m}^{2}\right)$. WC was measured from the front at the narrowest point between the rib cage and the iliac crest when the subject was breathing out gently.

Smoking habits, comorbidities and race/ethnicity were documented at study entry. Ethnicity was obtained separately from race. The ethnicity was classified as hispanic/ latino or not hispanic/latino; the race was classified as Caucasian, Black, Asian, or Other.

All subjects gave written informed consent and the trial was approved by the relevant local ethical committees and was conducted in conformity with the declaration of Helsinki.

\section{Statistical analysis}

Data are presented as mean (standard deviation), median (interquartile range) or number (\%). To examine the categorical relationship between BMI and the clinical, epidemiological and biochemical variables, patients were divided into the following categories based on their BMI $\left(\mathrm{kg} / \mathrm{m}^{2}\right)$ : $<25.0$ (healthy weight), 25.0 to $<30$ (overweight), 30.0 to $<35.0$ (obesity grade I), 35.0 to $<40$ (obesity grade II), $\geq 40.0$ (obesity grade III) [11]. For the same purpose, WC was dichotomised as healthy/ unhealthy for both the National Cholesterol Education Program [adult treatment panel III criteria (ATPIII)] [12] ( $\geq 88 \mathrm{~cm}$ for females and $\geq 102 \mathrm{~cm}$ for males) and the International Joint Interim Statement for the Harmonization of the Metabolic Syndrome criteria (IISHMS) [13] (Caucasians, Blacks and Others: $\geq 94 \mathrm{~cm}$ males and $\geq 80 \mathrm{~cm}$ females; Hispanics and Asians: $\geq 90 \mathrm{~cm}$ males and $\geq 80 \mathrm{~cm}$ females) [14].

For statistical purposes, the percentage of patients with glycated haemoglobin (HbA1c) $\leq 8 \%(<63.9 \mathrm{mmol} / \mathrm{mol})$ was calculated as it is considered to be an appropriate target in populations with advanced micro- or macrovascular complications, and extensive comorbid conditions, and in those with long-standing diabetes in whom the general target of an HbA1c $<7.0 \%(<53.0 \mathrm{mmol} / \mathrm{mol})$ is difficult to attain $[15,16]$. Blood pressure (BP) measurements of $<140 / 80 \mathrm{mmHg}$, low-density lipoprotein cholesterol (LDL-C) $<2.6 \mathrm{mmol} / \mathrm{l}(100 \mathrm{mg} / \mathrm{dl})(<1.8 \mathrm{mmol} / \mathrm{l}$ [70 $\mathrm{mg} / \mathrm{dl}]$ in patients with previous CV events), highdensity lipoprotein cholesterol (HDL-C) $>1.3 \mathrm{mmol} / \mathrm{l}$ $(50 \mathrm{mg} / \mathrm{dl})$ in women and $>1.0 \mathrm{mmol} / \mathrm{l}(40 \mathrm{mg} / \mathrm{dl})$ in men and triglycerides $<1.7 \mathrm{mmol} / \mathrm{l}(150 \mathrm{mg} / \mathrm{dl})$ were considered to be at target, according to the American Diabetes 
Association 2014 guidelines (the guidelines available when this analysis was conducted) [15].

Associations between BMI or WC with covariates and factors were screened initially using Spearman correlation and Chi square or Fisher's exact test, respectively. Linear regression models were used to describe the associations of treatment intensity/metabolic variables with anthropometric measurements. Likewise, logistic regression models were developed to assess the association between dichotomised "off-target" anthropometric variables and explanatory factors. Variable selection was decided before model fitting; in particular, BMI was excluded from the analysis of $\mathrm{WC}$ and vice versa (an overview of variables used in the logistic regression model is provided in the data table). Covariates were selected by consideration of potential impact on anthropometric measurements, based on review of the literature and availability in the LEADER database. Main effects of all covariates/factors were retained in the model, as the sample size of the LEADER study implied no need for further variable selection.

This study is based on the data from all 9340 participants in the LEADER trial, but numbers may vary due to missing data for a small number of participants. Complete data are available for approximately $99 \%$ of participants. Individuals with missing data were not included in the statistical analyses.

A two-sided $\mathrm{p}$ value of $<0.01$ was considered statistically significant. Statistical analyses were performed using SAS 9.3 software (SAS Institute, Cary, NC, USA). Analyses were conducted on the data available at baseline.

\section{Results}

\section{Demographic and clinical characteristics}

Baseline characteristics of all randomised patients stratified by prior CVD, BMI and WC are detailed in Tables 1-3.

\section{Stratified by CVD}

Mean BMI was comparable between patients with prior CVD and those without (32.5 vs. $32.4 \mathrm{~kg} / \mathrm{m}^{2}$, respectively). Comparing patients with prior CVD with those without, the prevalence of overweight (28.3 vs. $29.7 \%$, respectively), obesity grade I (32.3 vs. $30.6 \%$, respectively), obesity grade II (18.5 vs. $17.7 \%$, respectively), and obesity grade III (11.6 vs. $12.0 \%$, respectively) was similar (Table 1). Likewise, comparing patients with prior CVD with those without mean WC (110.1 and $109.4 \mathrm{~cm}$, respectively) and the overall prevalence of abdominal obesity according to ATPIII (78.1 and $80.0 \%$,
Table 1 Demographic and clinical characteristics stratified by CVD

\begin{tabular}{|c|c|c|c|}
\hline & $\begin{array}{l}\text { All } \\
(n=9340)\end{array}$ & $\begin{array}{l}\text { No prior CVD } \\
\text { group } \\
(n=1748)\end{array}$ & $\begin{array}{l}\text { Prior CVD } \\
\text { group } \\
(n=7592)\end{array}$ \\
\hline Age (years) & $64.3 \pm 7.2$ & $65.8 \pm 5.2$ & $63.9 \pm 7.6$ \\
\hline \multicolumn{4}{|l|}{ Gender } \\
\hline Female & 3337 (35.7\%) & $793(45.4 \%)$ & $2544(33.5 \%)$ \\
\hline Male & $6003(64.3 \%)$ & $955(54.6 \%)$ & $5048(66.5 \%)$ \\
\hline \multicolumn{4}{|l|}{ Age group } \\
\hline 50-59 years & $2321(24.9 \%)$ & $26(1.5 \%)$ & $2295(30.2 \%)$ \\
\hline $60-69$ years & 4839 (51.8\%) & 1337 (76.5 \%) & $3502(46.1 \%)$ \\
\hline 70-79 years & 1977 (21.2 \%) & 359 (20.5\%) & $1618(21.3 \%)$ \\
\hline $80-89$ years & 199 (2.1\%) & $26(1.5 \%)$ & $173(2.3 \%)$ \\
\hline 90-99 years & $4(0.0 \%)$ & $0(0.0 \%)$ & $4(0.1 \%)$ \\
\hline \multicolumn{4}{|l|}{ BMI $\left(\mathrm{kg} / \mathrm{m}^{2}\right)$} \\
\hline$<25.0$ & 865 (9.3\%) & $172(9.8 \%)$ & $693(9.1 \%)$ \\
\hline 25 to $<30$ & 2671 (28.6 \%) & $520(29.7 \%)$ & $2151(28.3 \%)$ \\
\hline 30 to $<35$ & 2987 (32.0 \%) & $535(30.6 \%)$ & $2452(32.3 \%)$ \\
\hline 35 to $<40$ & 1715 (18.4 \%) & $310(17.7 \%)$ & $1405(18.5 \%)$ \\
\hline$\geq 40.0$ & 1092 (11.7\%) & $210(12.0 \%)$ & $882(11.6 \%)$ \\
\hline \multicolumn{4}{|l|}{ WC ATIII target } \\
\hline Yes & 1933 (20.7 \%) & $338(19.3 \%)$ & $1595(21.0 \%)$ \\
\hline No & 7330 (78.5 \%) & 1398 (80.0 \%) & $5932(78.1 \%)$ \\
\hline Missing values & 77 (0.8 \%) & 12 (0.7 \%) & $65(0.9 \%)$ \\
\hline \multicolumn{4}{|l|}{ WC-IISHMS target } \\
\hline Yes & $585(6.3 \%)$ & $100(5.7 \%)$ & 485 (6.4\%) \\
\hline No & 8678 (92.9 \%) & 1636 (93.6 \%) & $7042(92.8 \%)$ \\
\hline Missing values & $77(0.8)$ & $12(0.7)$ & $65(0.9 \%)$ \\
\hline $\mathrm{HbA1c}(\%)$ & $8.7(1.6)$ & $8.8(1.5)$ & $8.7(1.6)$ \\
\hline $\mathrm{HbA1c}(\mathrm{mmol} / \mathrm{mol})$ & $71.6(17.5)$ & $72.7(16.4)$ & $71.6(17.5)$ \\
\hline \multicolumn{4}{|l|}{ Blood lipids } \\
\hline LDL-C (mmol/L) & $2.3(0.9)$ & $2.5(0.9)$ & $2.3(0.9)$ \\
\hline $\mathrm{HDL}-\mathrm{C}(\mathrm{mmol} / \mathrm{L})$ & $1.2(0.3)$ & $1.2(0.3)$ & $1.2(0.3)$ \\
\hline Triglycerides (mmol/L) & $2.1(1.6)$ & $2.0(1.5)$ & $2.1(1.6)$ \\
\hline No OAD use at baseline & 4409 (47.2 \%) & $744(42.6 \%)$ & $3665(48.3 \%)$ \\
\hline \multicolumn{4}{|l|}{ Pre-treatment } \\
\hline None/diet & $504(5.4)$ & $99(5.7)$ & $405(5.3)$ \\
\hline Insulines only & $665(7.1)$ & $69(3.9)$ & $596(7.9)$ \\
\hline OADs only & $4931(52.8)$ & $1004(57.4)$ & $3927(51.7)$ \\
\hline Ins + OADs & $3240(34.7)$ & $576(33.0)$ & $2644(35.1)$ \\
\hline \multicolumn{4}{|c|}{ Use of antihypertensive medication } \\
\hline Yes & $8550(91.5 \%)$ & $1473(84.3 \%)$ & $7077(93.2 \%)$ \\
\hline No & $790(8.5 \%)$ & $275(15.7 \%)$ & $515(6.8 \%)$ \\
\hline
\end{tabular}

Values are expressed as mean \pm SD or frequency (percent of row). ATPIII Adult treatment panel III criteria; CVD cardiovascular disease; eGFR estimated glomerular filtration rate; $\mathrm{HbA1c}$ glycated haemoglobin; $\mathrm{HDL}-\mathrm{C}$ high-density lipoprotein cholesterol; IISHMS International Joint Interim Statement for the Harmonization of the Metabolic Syndrome criteria; LDL-C low-density lipoprotein cholesterol; $S D$ standard deviation; $W C$ waist circumference 
Table 2 Demographic and clinical characteristics stratified by BMI

\begin{tabular}{|c|c|c|c|c|c|c|}
\hline & $\begin{array}{l}\text { All } \\
(n=9330)\end{array}$ & $\begin{array}{l}<25 \mathrm{~kg} / \mathrm{m}^{2} \\
(\mathrm{n}=865)\end{array}$ & $\begin{array}{l}25 \text { to }<30 \mathrm{~kg} / \mathrm{m}^{2} \\
(\mathrm{n}=2671)\end{array}$ & $\begin{array}{l}30 \text { to }<35 \mathrm{~kg} / \mathrm{m}^{2} \\
(\mathrm{n}=2987)\end{array}$ & $\begin{array}{l}35 \text { to }<40 \mathrm{~kg} / \mathrm{m}^{2} \\
(\mathrm{n}=1715)\end{array}$ & $\begin{array}{l}\geq 40.0 \mathrm{~kg} / \mathrm{m}^{2} \\
(\mathrm{n}=1092)\end{array}$ \\
\hline Age (years) & $64.3 \pm 7.2$ & $64.7 \pm 7.7$ & $65.4 \pm 7.4$ & $64.4 \pm 7.2$ & $63.4 \pm 6.8$ & $62.5 \pm 6.6$ \\
\hline \multicolumn{7}{|l|}{ Gender } \\
\hline Female & 3331 & $262(7.9 \%)$ & 817 (24.5 \%) & 995 (29.9\%) & 706 (21.2 \%) & $551(16.5 \%)$ \\
\hline Male & 5999 & 603 (10.1\%) & 1854 (30.9 \%) & 1992 (33.2 \%) & 1009 (16.8\%) & 541 (9.0\%) \\
\hline \multicolumn{7}{|l|}{ Age group } \\
\hline $50-59$ years & 2317 & 201 (8.7 \%) & $566(24.4 \%)$ & 729 (31.5 \%) & 476 (20.5 \%) & 345 (14.9\%) \\
\hline $60-69$ years & 4834 & 435 (9.0 \%) & 1327 (27.5 \%) & 1548 (32.0 \%) & 922 (19.1 \%) & $602(12.5 \%)$ \\
\hline $70-79$ years & 1976 & 201 (10.2 \%) & $697(35.3 \%)$ & 646 (32.7 \%) & 298 (15.1 \%) & 135 (6.8\%) \\
\hline $80-89$ years & 199 & $26(13.1 \%)$ & $80(40.2 \%)$ & 64 (32.2\%) & $19(9.5 \%)$ & 10 (5.0\%) \\
\hline 90-99 years & 4 & $3(75.0 \%)$ & $1(25.0 \%)$ & $0(0.0 \%)$ & $0(0.0 \%)$ & $0(0.0 \%)$ \\
\hline \multicolumn{7}{|l|}{ Region } \\
\hline Europe & 3517 & 206 (5.9\%) & 1019 (29.0 \%) & 1240 (35.3 \%) & 667 (19.0\%) & 385 (10.9\%) \\
\hline Other areas & 2616 & 276 (10.6 \%) & 807 (30.8 \%) & 830 (31.7 \%) & 457 (17.5 \%) & 246 (9.4\%) \\
\hline United States & 2487 & $120(4.8 \%)$ & $529(21.3 \%)$ & 811 (32.6\%) & $569(22.9 \%)$ & $458(18.4 \%)$ \\
\hline Asia & 710 & $263(37.0 \%)$ & 316 (44.5\%) & $106(14.9 \%)$ & $22(3.1 \%)$ & $3(0.4 \%)$ \\
\hline \multicolumn{7}{|l|}{ Race } \\
\hline Asian & 920 & $326(35.4 \%)$ & 395 (42.9\%) & $159(17.3 \%)$ & $33(3.6 \%)$ & $7(0.8 \%)$ \\
\hline Black & 773 & 53 (6.9\%) & 225 (29.1 \%) & 227 (29.4 \%) & 155 (20.1 \%) & $113(14.6 \%)$ \\
\hline Other & 406 & 57 (14.0\%) & $150(36.9 \%)$ & $118(29.1 \%)$ & $50(12.3 \%)$ & $31(7.6 \%)$ \\
\hline Caucasian & 7231 & 429 (5.9\%) & 1901 (26.3 \%) & 2483 (34.3 \%) & 1477 (20.4 \%) & $941(13.0 \%)$ \\
\hline \multicolumn{7}{|l|}{ Ethnicity } \\
\hline Hispanic or latino & 1135 & $131(11.5 \%)$ & $393(34.6 \%)$ & 357 (31.5 \%) & $166(14.6 \%)$ & $88(7.8 \%)$ \\
\hline Not hispanic or latino & 8195 & $734(9.0 \%)$ & $2278(27.8 \%)$ & 2630 (32.1\%) & 1549 (18.9\%) & $1004(12.3 \%)$ \\
\hline \multicolumn{7}{|l|}{ eGFR category $\left(\mathrm{mL} / \mathrm{min} / 1.73 \mathrm{~m}^{2}\right)$} \\
\hline Normal $(\geq 90)$ & 3445 & $367(10.7 \%)$ & $983(28.5 \%)$ & 1050 (30.5\%) & $670(19.4 \%)$ & $375(10.9 \%)$ \\
\hline Mild (60-90) & 3854 & $304(7.9 \%)$ & $1119(29.0 \%)$ & 1299 (33.7 \%) & $694(18.0 \%)$ & $438(11.4 \%)$ \\
\hline Moderate (30-60) & 1852 & $171(9.2 \%)$ & $510(27.5 \%)$ & $600(32.4 \%)$ & $322(17.4 \%)$ & $249(13.4 \%)$ \\
\hline Severe $(<30)$ & 177 & $23(13.0 \%)$ & $58(32.8 \%)$ & $37(20.9 \%)$ & $29(16.4 \%)$ & $30(16.9 \%)$ \\
\hline \multicolumn{7}{|l|}{ Smoker } \\
\hline Current smoker & 1128 & $122(10.8 \%)$ & $351(31.1 \%)$ & $359(31.8 \%)$ & $174(15.4 \%)$ & $122(10.8 \%)$ \\
\hline Never smoked & 3867 & $422(10.9 \%)$ & $1108(28.7 \%)$ & $1172(30.3 \%)$ & $718(18.6 \%)$ & $447(11.6 \%)$ \\
\hline Previous smoker & 4335 & $321(7.4 \%)$ & $1212(28.0 \%)$ & $1456(33.6 \%)$ & $826(19.1 \%)$ & $523(12.1 \%)$ \\
\hline \multicolumn{7}{|l|}{ CVD stratum } \\
\hline No Prior CVD group & 1747 & $172(9.8 \%)$ & $520(29.8 \%)$ & 535 (30.6\%) & $310(17.7 \%)$ & $210(12.0 \%)$ \\
\hline Prior CVD group & 7583 & $693(9.1 \%)$ & $2151(28.4 \%)$ & $2452(32.3 \%)$ & 1405 (18.5\%) & $882(11.6 \%)$ \\
\hline Diabetes duration (years) & $12.7 \pm 9.5$ & $14.1 \pm 8.8$ & $13.5 \pm 8.2$ & $12.4 \pm 7.8$ & $12.0 \pm 7.7$ & $12.1 \pm 7.7$ \\
\hline $\mathrm{HbA1c}(\%)$ & $8.7 \pm 1.5$ & $8.9 \pm 1.8$ & $8.6 \pm 1.5$ & $8.6 \pm 1.5$ & $8.7 \pm 1.5$ & $8.7 \pm 1.5$ \\
\hline $\mathrm{HbA} 1 \mathrm{c}(\mathrm{mmol} / \mathrm{mol})$ & $(71.6 \pm 16.4)$ & $(73.8 \pm 19.7)$ & $(70.5 \pm 16.4)$ & $(70.5 \pm 16.4)$ & $(71.6 \pm 16.4)$ & $(71.6 \pm 16.4)$ \\
\hline \multicolumn{7}{|l|}{ Blood lipids } \\
\hline $\mathrm{LDL}-\mathrm{C}(\mathrm{mmol} / \mathrm{L})$ & $2.3 \pm 0.9$ & $2.3 \pm 0.5$ & $2.3 \pm 0.9$ & $2.3 \pm 0.9$ & $2.3 \pm 0.9$ & $2.3 \pm 0.9$ \\
\hline $\mathrm{HDL}-\mathrm{C}(\mathrm{mmol} / \mathrm{L})$ & $1.2 \pm 0.3$ & $1.2 \pm 0.4$ & $1.2 \pm 0.3$ & $1.1 \pm 0.3$ & $1.2 \pm 0.3$ & $1.2 \pm 0.3$ \\
\hline Triglycerides (mmol/L) & $2.1 \pm 1.6$ & $1.6 \pm 1.1$ & $1.9 \pm 1.5$ & $2.2 \pm 1.8$ & $2.2 \pm 1.4$ & $2.2 \pm 1.7$ \\
\hline \multicolumn{7}{|l|}{ Blood pressure } \\
\hline Systolic blood pressure (mmHg) & $137.7 \pm 18.6$ & $134.5 \pm 19.2$ & $137.9 \pm 18.5$ & $138.3 \pm 18.5$ & $138.1 \pm 18.2$ & $137.5 \pm 19.3$ \\
\hline Diastolic blood pressure $(\mathrm{mmHg})$ & $77.9 \pm 10.5$ & $76.4 \pm 9.9$ & $77.1 \pm 10.2$ & $78.3 \pm 10.4$ & $78.9 \pm 10.4$ & $78.3 \pm 11.5$ \\
\hline
\end{tabular}

Values are expressed as mean \pm SD or frequency (percent of row). BMI body mass index; CVD cardiovascular disease; eGFR estimated glomerular filtration rate; HbA1c glycated haemoglobin; HDL-C high-density lipoprotein cholesterol; $L D L-C$ low-density lipoprotein cholesterol; $S D$ standard deviation 
Table 3 Demographic and clinical characteristics stratified by WC according ATPIII and IISHMS

\begin{tabular}{|c|c|c|c|c|c|}
\hline & \multirow{2}{*}{$\begin{array}{l}\text { All } \\
(n=9263)\end{array}$} & \multicolumn{2}{|l|}{ WC-ATPIII } & \multicolumn{2}{|l|}{ WC-IISHMS } \\
\hline & & $\begin{array}{l}\text { Off target } \\
(n=7330)\end{array}$ & $\begin{array}{l}\text { On target } \\
(n=1933)\end{array}$ & $\begin{array}{l}\text { Off target } \\
(\mathrm{n}=8678)\end{array}$ & $\begin{array}{l}\text { On target } \\
(n=585)\end{array}$ \\
\hline Age (years) & $64.3 \pm 7.2$ & $64.3 \pm 7.2$ & $64.3 \pm 7.4$ & $64.3 \pm 7.2$ & $64.2 \pm 7.4$ \\
\hline \multicolumn{6}{|l|}{ Gender } \\
\hline Female & 3305 & 3050 (92.3 \%) & 255 (7.7\%) & 3232 (97.8 \%) & 73 (2.2 \%) \\
\hline Male & 5958 & 4280 (71.8\%) & 1678 (28.2 \%) & 5446 (91.4 \%) & 512 (8.6 \%) \\
\hline \multicolumn{6}{|l|}{ Age group } \\
\hline 50-59 years & 2305 & 1822 (79.0 \%) & 483 (21.0 \%) & 2165 (93.9\%) & 140 (6.1%) \\
\hline $60-69$ years & 4806 & 3835 (79.8 \%) & 971 (20.2 \%) & 4501 (93.7 \%) & 305 (6.3 \%) \\
\hline 70-79 years & 1954 & 1518 (77.7 \%) & 436 (22.3 \%) & 1829 (93.6 \%) & 125 (6.4\%) \\
\hline $80-89$ years & 194 & 153 (78.9\%) & 41 (21.1 \%) & 180 (92.8 \%) & $14(7.2 \%)$ \\
\hline 90-99 years & 4 & $2(50.0 \%)$ & $2(50.0 \%)$ & $3(75.0 \%)$ & $1(25.0 \%)$ \\
\hline \multicolumn{6}{|l|}{ Region } \\
\hline Europe & 3489 & 2873 (82.3 \%) & 616 (17.7\%) & 3322 (95.2 \%) & 167 (4.8\%) \\
\hline Other areas & 2600 & 2053 (79.0 \%) & 547 (21.0 \%) & 2449 (94.2 \%) & 151 (5.8\%) \\
\hline United States & 2465 & 2092 (84.9\%) & 373 (15.1 \%) & 2345 (95.1\%) & 120 (4.9\%) \\
\hline Asia & 709 & 312 (44.0 \%) & 397 (56.0 \%) & $562(79.3 \%)$ & $147(20.7 \%)$ \\
\hline \multicolumn{6}{|l|}{ Race } \\
\hline Asian & 919 & 420 (45.7 \%) & 499 (54.3 \%) & 741 (80.6 \%) & $178(19.4 \%)$ \\
\hline Black & 771 & 632 (82.0 \%) & 139 (18.0\%) & 725 (94.0 \%) & $46(6.0 \%)$ \\
\hline Other & 403 & 298 (73.9 \%) & 105 (26.1 \%) & 374 (92.8 \%) & $29(7.2 \%)$ \\
\hline Caucasian & 7170 & 5980 (83.4 \%) & 1190 (16.6\%) & 6838 (95.4 \%) & 332 (4.6\%) \\
\hline \multicolumn{6}{|l|}{ Ethnicity } \\
\hline Hispanic or latino & 1127 & $840(74.5 \%)$ & $287(25.5 \%)$ & 1070 (94.9\%) & $57(5.1 \%)$ \\
\hline Not hispanic or latino & 8136 & $6490(79.8 \%)$ & $1646(20.2 \%)$ & 7608 (93.5 \%) & $528(6.5 \%)$ \\
\hline \multicolumn{6}{|l|}{ eGFR category (mL/min/1.73 m²) } \\
\hline Normal $(\geq 90)$ & 3415 & $2654(77.7 \%)$ & $761(22.3 \%)$ & $3183(93.2 \%)$ & $232(6.8 \%)$ \\
\hline Mild (60-90) & 3831 & 3068 (80.1 \%) & $763(19.9 \%)$ & 3590 (93.7 \%) & $241(6.3 \%)$ \\
\hline Moderate (30-60) & 1842 & $1475(80.1 \%)$ & $367(19.9 \%)$ & 1742 (94.6\%) & $100(5.4 \%)$ \\
\hline Severe $(<30)$ & 173 & $132(76.3 \%)$ & $41(23.7 \%)$ & 161 (93.1\%) & $12(6.9 \%)$ \\
\hline \multicolumn{6}{|l|}{ Smoker } \\
\hline Current smoker & 1117 & $833(74.6 \%)$ & $284(25.4 \%)$ & $1023(91.6 \%)$ & $94(8.4 \%)$ \\
\hline Never smoked & 3852 & $3057(79.4 \%)$ & $795(20.6 \%)$ & 3611 (93.7 \%) & $241(6.3 \%)$ \\
\hline Previous smoker & 4294 & $3440(80.1 \%)$ & $854(19.9 \%)$ & 4044 (94.2 \%) & $250(5.8 \%)$ \\
\hline \multicolumn{6}{|l|}{ CVD stratum } \\
\hline No prior CVD group & 1736 & $1398(80.5 \%)$ & $338(19.5 \%)$ & $1636(94.2 \%)$ & $100(5.8 \%)$ \\
\hline Prior CVD group & 7527 & $5932(78.8 \%)$ & $1595(21.2 \%)$ & 7042 (93.6 \%) & 485 (6.4\%) \\
\hline Diabetes duration (years) & $12.7 \pm 8.0$ & $12.5 \pm 8.0$ & $13.5 \pm 8.3$ & $12.6 \pm 8.0$ & $13.9 \pm 8.7$ \\
\hline $\mathrm{HbA1c}(\%)$ & $8.7 \pm 1.5$ & $8.7 \pm 1.5$ & $8.7 \pm 1.6$ & $8.7 \pm 1.5$ & $8.7 \pm 1.7$ \\
\hline $\mathrm{HbA1c}(\mathrm{mmol} / \mathrm{mol})$ & $(71.6 \pm 16.4)$ & $(71.6 \pm 16.4)$ & $(71.6 \pm 17.5)$ & $(71.6 \pm 16.4)$ & $(71.6 \pm 18.6)$ \\
\hline \multicolumn{6}{|l|}{ Blood lipids } \\
\hline $\mathrm{LDL}-\mathrm{C}(\mathrm{mmol} / \mathrm{L})$ & $2.3 \pm 0.9$ & $2.3 \pm 0.9$ & $2.3 \pm 0.9$ & $2.3 \pm 0.9$ & $2.2 \pm 0.9$ \\
\hline $\mathrm{HDL}-\mathrm{C}(\mathrm{mmol} / \mathrm{L})$ & $1.2 \pm 0.3$ & $1.2 \pm 0.3$ & $1.2 \pm 0.3$ & $1.2 \pm 0.3$ & $1.3 \pm 0.4$ \\
\hline Triglycerides (mmol/L) & $2.1 \pm 1.6$ & $2.1 \pm 1.6$ & $1.7 \pm 1.5$ & $2.1 \pm 1.6$ & $1.6 \pm 1.6$ \\
\hline \multicolumn{6}{|l|}{ Blood pressure } \\
\hline Systolic blood pressure (mmHg) & $138 \pm 19$ & $138 \pm 19$ & $136 \pm 19$ & $138 \pm 19$ & $135 \pm 18$ \\
\hline Diastolic blood pressure $(\mathrm{mmHg})$ & $78 \pm 11$ & $78 \pm 11$ & $77 \pm 10$ & $78 \pm 11$ & $76 \pm 10$ \\
\hline
\end{tabular}

Values are expressed as mean \pm SD or frequency (percent of row). ATPIII Adult Treatment Panel III criteria; CVD cardiovascular disease; eGFR estimated glomerular filtration rate; $\mathrm{HbA1c}$ glycated haemoglobin; $H D L-C$ high-density lipoprotein cholesterol; IISHMS International Joint Interim Statement for the Harmonization of the Metabolic Syndrome criteria; LDL-C low-density lipoprotein cholesterol; SD standard deviation; WC waist circumference 
respectively) and IISHMS (92.8 and $93.6 \%$, respectively) was also similar.

Female gender was less prevalent in the prior CVD cohort than those without prior CVD (33.5 vs. $45.4 \%$, respectively). There was also a lower prevalence of patients aged 60-69 years with prior CVD than patients without (46.1 vs. $76.5 \%$, respectively), and a higher proportion of patients aged 50-59 years with prior CVD than patients without (30.2 vs. $1.5 \%$, respectively). Furthermore, there was also a lower prevalence of patients at target LDL-C with prior CVD than those without (33.2 vs. $56.6 \%$, respectively). Comparing patients with prior CVD with those without, there was a greater prevalence of patients not using oral antihyperglycaemic drugs (OADs) (48.3 vs. $42.6 \%$, respectively). Additionally, comparing patients with prior CVD with those without, there was a greater prevalence of patients using antihypertensive medication (93.2 vs. $84.3 \%$, respectively).

\section{Stratified by BMI and WC}

Mean BMI was $32.5 \pm 6.3 \mathrm{~kg} / \mathrm{m}^{2}$ and only $9.1 \%$ of patients had a BMI $<25 \mathrm{~kg} / \mathrm{m}^{2}$. The prevalence of overweight, obesity grade I, obesity grade II, and obesity grade III was 28.6, 32.0, 18.4 and $11.7 \%$, respectively (Table 2). The mean WC was $109.9 \pm 16.2 \mathrm{~cm}$ and the overall prevalence of abdominal obesity according to ATPIII and IISHMS was 79.1 and $93.6 \%$, respectively (Table 3 ).

BMI was higher in females than in males (BMI $33.6 \pm 6.8 \mathrm{~kg} / \mathrm{m}^{2}$ vs. $31.9 \pm 5.9 \mathrm{~kg} / \mathrm{m}^{2}$, respectively; $\mathrm{p}<0.0001)$. WC was lower in females than males $(107.6 \pm 15.6 \mathrm{~cm}$ vs. $111.2 \pm 16.3 \mathrm{~cm}$, respectively; $\mathrm{p}<0.0001)$. Moreover, due to gender-specific cutoffs, the prevalence of abdominal obesity was higher in females than males when measured independently from the WC criteria (ATPIII: 92.3 vs. $71.8 \%$; IISHMS 97.8 vs. $91.4 \%$, respectively; $\mathrm{p}<0.0001$ ).

Younger patients were heavier with age (per year) being inversely correlated with BMI $(\mathrm{p}<0.0001)$ and WC $(\mathrm{p}<0.0001)$. Similar patterns were observed among BMI categories.

The prevalence of prior CVD was similar across all BMI categories (80.1, 80.5, 82.1, 81.9 and $80.8 \%$, respectively; $\mathrm{p}=0.4491$ ) and WC categories for both criteria (ATPIII: 80.9 vs. $82.5 \%$; IISHMS: 81.1 vs. $82.9 \%$ ).

Twelve percent of patients were current smokers, and $46 \%$ were previous smokers. Tables 2 and 3 show that the prevalence of current smokers was higher, and the prevalence of previous smokers was lower in patients with normal BMI and WC when compared with higher BMI and WC categories.

A significant decrease in diabetes duration with increasing degrees of obesity was observed across BMI $(\mathrm{p}=0.0001)$ and $\mathrm{WC}(\mathrm{p}=0.0044)$ categories.
Obesity and overweight were more frequent in Caucasian and Black individuals than in Asian or "other" races. Thus, the prevalence of patients with BMI $<25 \mathrm{~kg} / \mathrm{m}^{2}$ among races was highest in Asian people followed by "Other race", Black and Caucasian people (35.4, 14.0, 6.9 and $5.9 \%$, respectively; $\mathrm{p}<0.0001$ ). Also, the percentage of subjects with healthy WC according to ATPIII and IISHMS was higher in Asian people following the same order as BMI (ATPIII: 54.3, 26.1, 18.0 and $16.6 \%$; IISHMS: 19.4, 7.2, 6.0 and $4.6 \%$; $p<0.0001$ ).

Regarding demographic areas, the highest prevalence of overweight and obesity and central adiposity was in the USA, followed by Europe, "Other areas" and Asia $(\mathrm{p}<0.0001)$. Consequently, the prevalence of normal weight in the USA, Europe, "Other areas" and Asia was $4.8,5.9,10.6$ and $14.0 \%$, respectively.

Similar patterns of association between obesity (according to BMI and WC categories), age, gender, prior CVD, tobacco use and diabetes duration were observed when different races and ethnicities were analysed separately.

\section{Cardiometabolic risk factors and medication use}

Cardiometabolic risk factors and medication use by BMI and WC categories are shown in Tables 2 and 3 and Figs. 1 and 2, respectively. A summary of the prevalence of patients for each BMI and WC class are provided in Fig. 3.

Unadjusted observed values for triglycerides (TG) were positively correlated with BMI $(\mathrm{p}<0.0001)$ and WC $(\mathrm{p}<0.0001)$. HDL-C was negatively correlated with BMI $(\mathrm{p}<0.0001)$ and WC $(\mathrm{p}<0.0001)$. Positive correlations were also found for BP with BMI and WC. No significant correlations were found between HbA1c and BMI or WC.

In the Chi squared analysis (unadjusted), the percentage of patients with target levels of TG, HDL-C and BP dropped significantly with increasing BMI (Fig. 1a). However in the case of HbA1c on target, this trend was reversed; the percentage of patients with HbAlc at target increased significantly with increasing BMI $\left(\right.$ BMI $>25 \mathrm{~kg} / \mathrm{m}^{2}$ ) (Fig. 1a). A similar trend was observed for both WC criteria (Fig. 1b).

Obese patients were more likely to be on insulin. The prevalence of patients on insulin was significantly lower in patients with normal weight (Fig. 2a) and normal abdominal waist circumference (Fig. 2b) compared with higher BMI and WC categories. There was a higher percentage of patients on OADs plus insulin at higher BMI $\left(>25 \mathrm{~kg} / \mathrm{m}^{2}\right)$ and off-target WC categories (Fig. 2).

In the same way, obese patients were more likely to be treated with statins and antihypertensive medication than those of normal weight. The prevalence of patients on these drugs was greater at higher BMI (Fig. 2a) and WC (Fig. 2b) categories. Also, patients with higher BMI $\left(>25 \mathrm{~kg} / \mathrm{m}^{2}\right)$ were taking a greater number of 


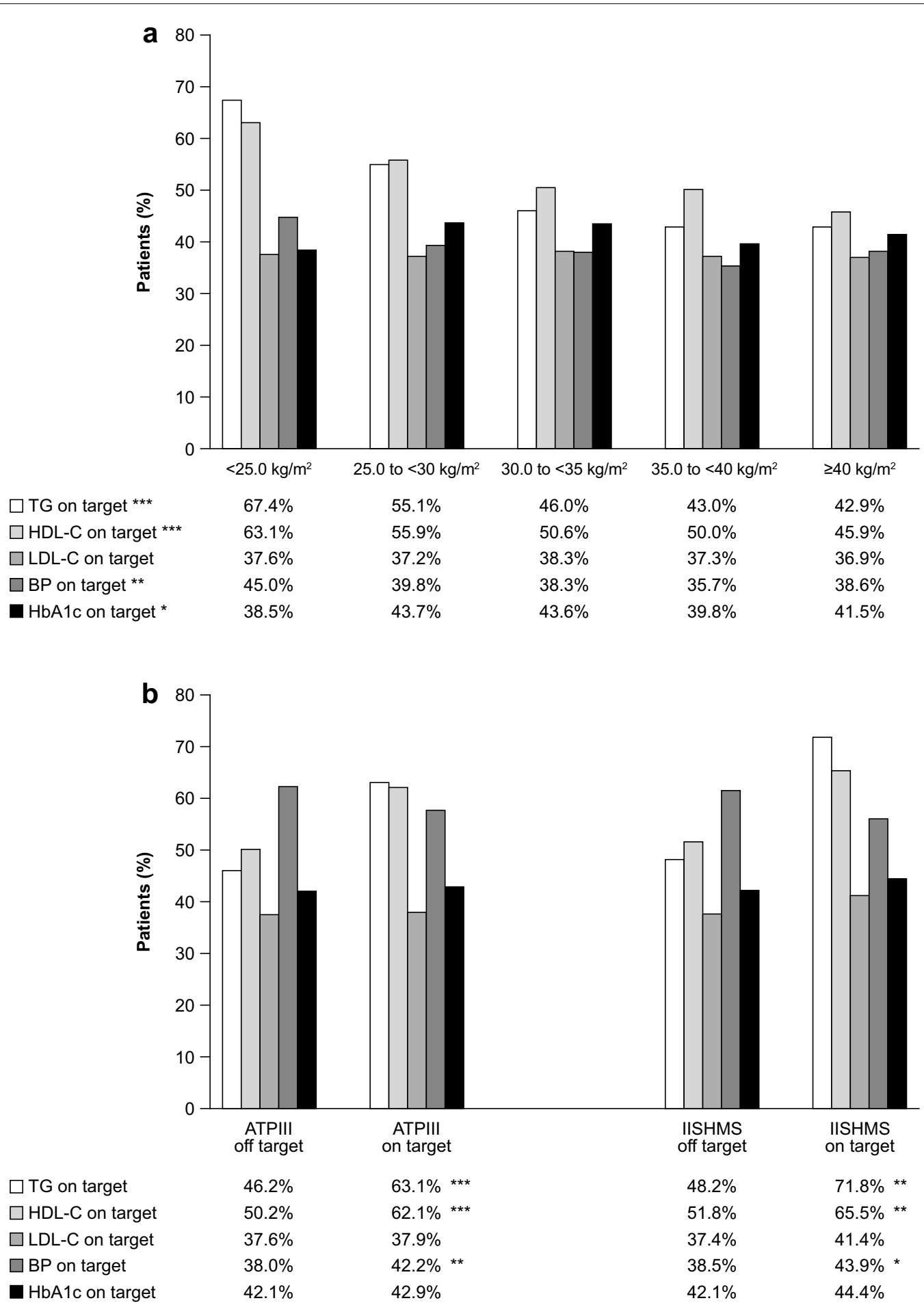

Fig. 1 Percentage of patients with cardiometabolic parameters at target among (a) BMI and (b) WC categories. Statistics. p values of BMI or WC vs. factors were calculated using Chi square test. ${ }^{* *} p<0.0001 ;{ }^{* *} p<0.001 ;{ }^{*} p<0.01$. ATPIII, adult treatment panel III criteria; BMI, body mass index; BP, blood pressure; HbA1c, glycated haemoglobin; HDL-C, high-density lipoprotein cholesterol; IISHMS, International Joint Interim Statement for the Harmonization of the Metabolic Syndrome criteria; LDL-C, low-density lipoprotein cholesterol; OADs, oral antihyperglycaemic drugs; TG, triglycerides; WC, waist circumference 



Fig. 2 Percentage of patients with relevant medication among (a) BMI and (b) WC categories. Statistics. p values of BMI or WC vs. factors were calculated using Chi square. ${ }^{* * *} p<0.0001 ;{ }^{* *} p<0.001 ;{ }^{*} p<0.01$. ATPIII, adult treatment panel III criteria; BMI, body mass index; IISHMS, International Joint Interim Statement for the Harmonization of the Metabolic Syndrome criteria; OADs, oral antihyperglycaemic drugs; WC, waist circumference

antihypertensive agents $(\mathrm{p}<0.0001)$. Despite the lipidmodifying therapy and higher numbers of antihypertensive drugs, the lipid profile and BP were worse in obese patients than in those of normal weight. On the contrary, no difference in glycaemic control (HbA1c) was found between BMI and WC categories. 


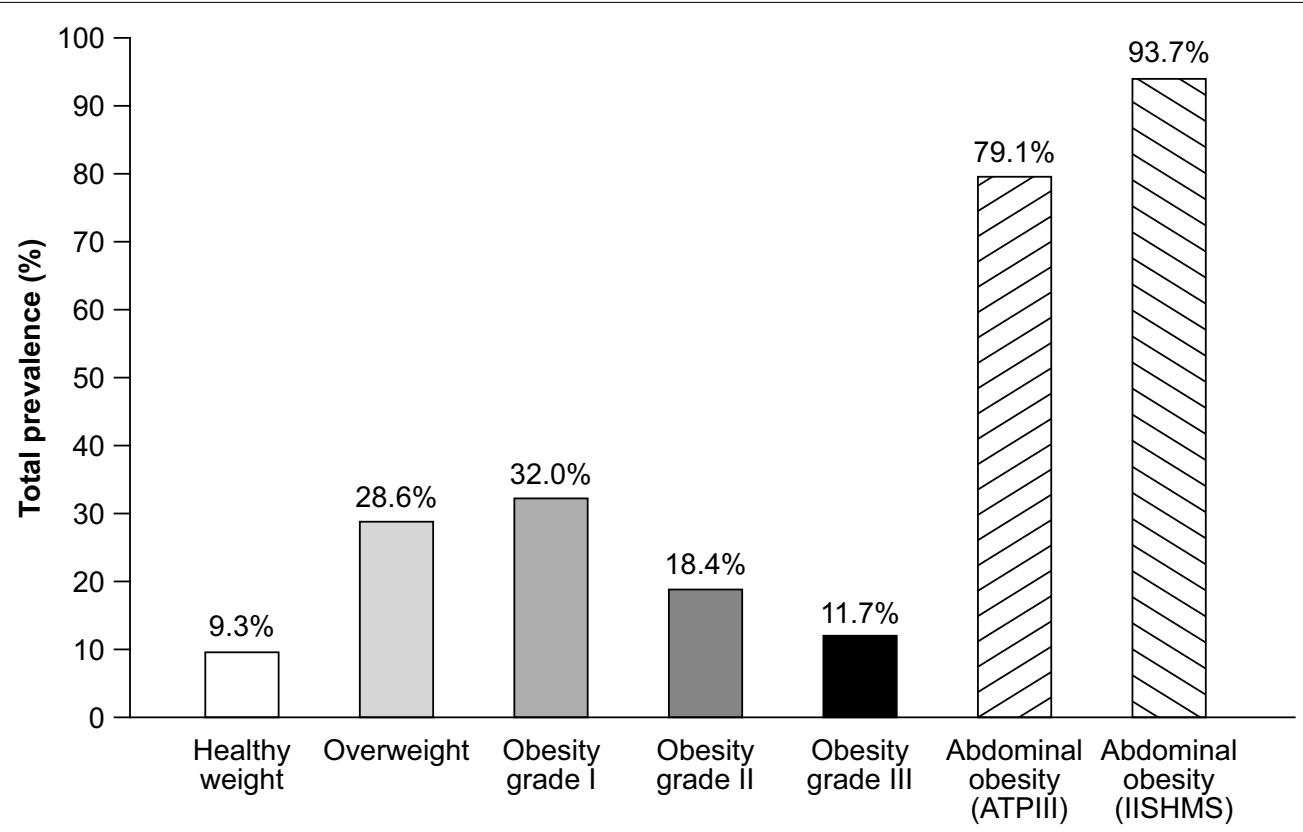

Fig. 3 Prevalence of patients who are overweight, obesity grade I, obesity grade II and obesity grade III* and with abdominal obesity. *The sum of the prevalence of patients in BMI obesity grades equal $100 \%$. ATPIII, adult treatment panel III criteria; BMI, body mass index; IISHMS, International Joint Interim Statement for the Harmonization of the Metabolic Syndrome criteria; WC, waist circumference

Multivariable logistic regressions modelling BMI and WC Multivariable binary logistic regression models using $\mathrm{BMI} \geq 30 \mathrm{~kg} / \mathrm{m}^{2}$ and off-target WC (using IISHMS and ATPIII) as dependent variables, and relevant demographic, clinical, cardiometabolic and medication parameters as independent variables, were performed in order to elucidate which variables were more related with being obese when having T2DM (Table 4). These analyses are adjusted data, providing the overall relationship of factors with obesity, and therefore supersede the unadjusted data.

As shown in Table 4, binary logistic regressions revealed that being obese $\left(\mathrm{BMI} \geq 30 \mathrm{~kg} / \mathrm{m}^{2}\right.$ ) was significantly associated with being younger, female, previous smoker (vs. current smoker), Caucasian (vs. Asian, Black or other races), not Hispanic or Latino (vs. not Hispanic or Latino), from the USA (vs. Asia, Europe, or other areas), shorter diabetes duration, having uncontrolled BP, reduced estimated glomerular filtration rate (eGFR), antihypertensive drug intake (four antihypertensive drugs vs. zero, one or two antihypertensive drugs), insulin plus OAD treatment (vs. OADs only), high levels of TG and lower levels of LDL-C and HDL-C.

Regarding WC, abdominal obesity according to ATPIII was significantly and positively related to the same variables as $\mathrm{BMI} \geq 30 \mathrm{~kg} / \mathrm{m}^{2}$, with the exception of age, reduced eGFR and no pre-treatment/diet only.
In contrast, when the IISHMS were applied, abdominal obesity was mainly related to being female (vs. male), previous smoker (vs. current smokers), Caucasian (vs. Asian), from the USA (vs. Asia or other areas), antihypertensive drug intake (four antihypertensive drugs vs. zero antihypertensive drugs), insulin plus OAD treatment (vs. OADs only), higher levels of TG and lower levels of HDL-C. The associations for hypertension and antihypertensive drug intake were less significant when considering IISHMS compared to ATPIII indicating that, at least for BP, the larger the abdominal circumference, the larger the cardiometabolic impact. There was no statistically significant relationship between HbA1c and the obesity criteria evaluated. Likewise, despite the relationship between eGFR and BMI, no correlation was determined between the albumin-creatinine ratio and BMI or WC criteria.

\section{Discussion}

Our principal finding is that in this very high-risk population of patients with T2DM, the prevalence of overweight (28.6\%) and obesity (61.7\%) is very high. Only $9.1 \%$ of the patients were of normal weight. Likewise, only 20.9 and $6.3 \%$ of patients had a healthy WC according to the ATPIII and IISHMS for metabolic syndrome, respectively. The baseline data from the LEADER trial gave us the opportunity to study the prevalence of overweight 
Table 4 An overview of multivariable logistic regression: baseline characteristics associated with obesity $\left(B M I \geq 30 \mathrm{~kg} / \mathrm{m}^{2}\right.$ ) and increased waist circumference (WC-ATPIII and WC-IISHMS) off target

\begin{tabular}{|c|c|c|c|c|c|c|c|c|c|}
\hline & \multicolumn{3}{|c|}{$\mathrm{BMI} \geq 30 \mathrm{~kg} / \mathrm{m}^{2}$} & \multicolumn{3}{|c|}{ WC-ATPIII off target } & \multicolumn{3}{|c|}{ WC-IISHMS off target } \\
\hline & Odds ratio & $95 \% \mathrm{Cl}$ for OR & p value & Odds ratio & (95\% Cl for OR) & p value & Odds ratio & (95 \% C.I. for OR) & $p$ value \\
\hline Age (per year) & 0.956 & $(0.949-0.964)$ & $<0.0001$ & 0.998 & $(0.988-1.007)$ & 0.6461 & 1.005 & $(0.990-1.021)$ & 0.5158 \\
\hline \multicolumn{10}{|l|}{ Gender } \\
\hline Male & 0.597 & $(0.525-0.678)$ & $<0.0001$ & 0.136 & $(0.112-0.164)$ & $<0.0001$ & 0.190 & $(0.137-0.259)$ & $<0.0001$ \\
\hline Female & 1.000 & $(1.000-1.000)$ & - & 1.000 & $(1.000-1.000)$ & - & 1.000 & $(1.000-1.000)$ & - \\
\hline \multicolumn{10}{|l|}{ Smoking status } \\
\hline Current smoker & 0.612 & $(0.517-0.724)$ & $<0.0001$ & 0.627 & $(0.516-0.764)$ & $<0.0001$ & 0.604 & $(0.453-0.813)$ & 0.0007 \\
\hline Never smoked & 0.927 & $(0.821-1.046)$ & 0.2189 & 0.797 & $(0.689-0.922)$ & 0.0022 & 0.911 & $(0.724-1.148)$ & 0.4295 \\
\hline Previous smoker & 1.000 & $(1.000-1.000)$ & - & 1.000 & $(1.000-1.000)$ & - & 1.000 & $(1.000-1.000)$ & - \\
\hline \multicolumn{10}{|l|}{ Region } \\
\hline Asia & 0.207 & $(0.137-0.314)$ & $<0.0001$ & 0.361 & $(0.240-0.543)$ & $<0.0001$ & 0.358 & $(0.199-0.625)$ & 0.0004 \\
\hline Europe & 0.500 & $(0.430-0.579)$ & $<0.0001$ & 0.685 & $(0.569-0.823)$ & 0.0001 & 0.901 & $(0.659-1.227)$ & 0.5106 \\
\hline Other areas & 0.495 & $(0.426-0.576)$ & $<0.0001$ & 0.646 & $(0.536-0.777)$ & $<0.0001$ & 0.683 & $(0.504-0.925)$ & 0.0140 \\
\hline United States & 1.000 & $(1.000-1.000)$ & - & 1.000 & $(1.000-1.000)$ & - & 1.000 & $(1.000-1.000)$ & - \\
\hline \multicolumn{10}{|l|}{ Race } \\
\hline Asian & 0.226 & $(0.159-0.317)$ & $<0.0001$ & 0.240 & $(0.168-0.341)$ & $<0.0001$ & 0.473 & $(0.290-0.803)$ & 0.0039 \\
\hline Black & 0.663 & $(0.545-0.808)$ & $<0.0001$ & 0.628 & $(0.493-0.804)$ & 0.0002 & 0.690 & $(0.474-1.020)$ & 0.0565 \\
\hline Other & 0.598 & $(0.465-0.771)$ & 0.0001 & 0.699 & $(0.521-0.944)$ & 0.0180 & 0.782 & $(0.482-1.324)$ & 0.3368 \\
\hline Caucasian & 1.000 & $(1.000-1.000)$ & - & 1.000 & $(1.000-1.000)$ & - & 1.000 & $(1.000-1.000)$ & - \\
\hline \multicolumn{10}{|l|}{ Ethnicity } \\
\hline Hispanic or latino & 0.528 & $(0.446-0.625)$ & $<0.0001$ & 0.545 & $(0.445-0.668)$ & $<0.0001$ & 1.121 & $(0.790-1.620)$ & 0.5311 \\
\hline Not hispanic or latino & 1.000 & $(1.000-1.000)$ & - & 1.000 & $(1.000-1.000)$ & - & 1.000 & $(1.000-1.000)$ & - \\
\hline $\mathrm{HbA} 1 \mathrm{c}(\mathrm{mmol} / \mathrm{mol})$ & 0.999 & $(0.995-1.002)$ & 0.4850 & 0.999 & $(0.995-1.003)$ & 0.7628 & 0.995 & $(0.989-1.002)$ & 0.1402 \\
\hline Diabetes duration per year & 0.983 & $(0.977-0.990)$ & $<0.0001$ & 0.981 & $(0.973-0.989)$ & $<0.0001$ & 0.982 & $(0.970-0.995)$ & 0.0051 \\
\hline \multicolumn{10}{|c|}{ Hypertension (>140/80 mm Hg) } \\
\hline No & 0.779 & $(0.696-0.871)$ & $<0.0001$ & 0.862 & $(0.754-0.984)$ & 0.0281 & 0.862 & $(0.701-1.062)$ & 0.1623 \\
\hline Yes & 1.000 & $(1.000-1.000)$ & - & 1.000 & $(1.000-1.000)$ & - & 1.000 & $(1.000-1.000)$ & - \\
\hline \multicolumn{10}{|l|}{ Blood lipids } \\
\hline $\mathrm{LDL}-\mathrm{C}(\mathrm{mmol} / \mathrm{L})$ & 0.903 & $(0.848-0.963)$ & 0.0018 & 0.914 & $(0.845-0.988)$ & 0.0234 & 1.029 & $(0.907-1.170)$ & 0.6590 \\
\hline $\mathrm{HDL}-\mathrm{C}(\mathrm{mmol} / \mathrm{L})$ & 0.620 & $(0.511-0.752)$ & $<0.0001$ & 0.516 & $(0.411-0.646)$ & $<0.0001$ & 0.416 & $(0.303-0.574)$ & $<0.0001$ \\
\hline Triglycerides (mmol/L) & 1.278 & $(1.192-1.370)$ & $<0.0001$ & 1.417 & $(1.298-1.548)$ & $<0.0001$ & 1.680 & $(1.438-1.974)$ & $<0.0001$ \\
\hline $\mathrm{eGFR}\left(\mathrm{mL} / \mathrm{min} / 1.73 \mathrm{~m}^{2}\right)$ & 0.998 & $(0.996-1.000)$ & 0.0209 & 1.001 & $(0.998-1.003)$ & 0.6185 & 1.001 & $(0.997-1.005)$ & 0.5649 \\
\hline $\begin{array}{l}\text { Albumin-creatinine ratio } \\
\text { (per doubling) }\end{array}$ & 0.994 & $(0.971-1.017)$ & 0.5823 & 1.016 & $(0.989-1.044)$ & 0.2459 & 1.012 & $(0.970-1.055)$ & 0.5866 \\
\hline \multicolumn{10}{|c|}{ Number of antihypertensive drugs } \\
\hline 0 & 0.306 & $(0.217-0.428)$ & $<0.0001$ & 0.320 & $(0.207-0.483)$ & $<0.0001$ & 0.364 & $(0.175-0.693)$ & 0.0037 \\
\hline 1 & 0.558 & $(0.411-0.751)$ & 0.0002 & 0.543 & $(0.364-0.790)$ & 0.0020 & 0.757 & $(0.374-1.390)$ & 0.4013 \\
\hline 2 & 0.599 & $(0.443-0.801)$ & 0.0007 & 0.615 & $(0.415-0.890)$ & 0.0125 & 0.686 & $(0.343-1.244)$ & 0.2484 \\
\hline 3 & 0.862 & $(0.627-1.175)$ & 0.3546 & 0.860 & $(0.567-1.277)$ & 0.4659 & 1.217 & $(0.580-2.361)$ & 0.5793 \\
\hline 4 & 1.000 & $(1.000-1.000)$ & - & 1.000 & $(1.000-1.000)$ & - & 1.000 & $(1.000-1.000)$ & - \\
\hline \multicolumn{10}{|l|}{ Pretreatment } \\
\hline Insulin + OADs & 1.298 & $(1.153-1.463)$ & $<0.0001$ & 1.281 & $(1.110-1.480)$ & 0.0007 & 1.525 & $(1.213-1.926)$ & 0.0003 \\
\hline Insulins use & 1.022 & $(0.826-1.266)$ & 0.8418 & 1.040 & $(0.808-1.345)$ & 0.7625 & 1.196 & $(0.804-1.830)$ & 0.3931 \\
\hline None/diet & 1.297 & $(1.018-1.660)$ & 0.0372 & 1.174 & $(0.881-1.582)$ & 0.2821 & 1.208 & (0.779-1.949) & 0.4189 \\
\hline OADs use & 1.000 & $(1.000-1.000)$ & - & 1.000 & $(1.000-1.000)$ & - & 1.000 & $(1.000-1.000)$ & - \\
\hline
\end{tabular}

The full list of variables used were age, sex, smoking status, region, race, ethnicity, CVD stratum, diabetes duration, HbA1c, hypertension, number of antihypertensive drugs, eGFR, LDL-C, HDL-C, triglycerides, albumin/creatinine ratio, statin use, hyperlipidaemia, aspirin use and number of previous antihypertensive agents. ATPIII Adult treatment panel III criteria; $B M I$ body mass index; eGFR estimated glomerular filtration rate; $H b A 1 c$ glycated haemoglobin; $H D L-C$ high-density lipoprotein cholesterol; IISHMS International Joint Interim Statement for the Harmonization of the Metabolic Syndrome criteria; LDL-C low-density lipoprotein cholesterol; OADs oral antihyperglycaemic drugs; SD standard deviation; WC waist circumference 
and obesity in a high CV risk population with T2DM, and also the association with a set of cardiometabolic risk factors and their treatment intensity.

Worldwide, the proportion of adults with $B M I \geq 25 \mathrm{~kg} / \mathrm{m}^{2}$ is estimated to be $36.9 \%$ in men and $38.0 \%$ in women. These figures range from $20.2-22.5 \%$ in South Asia to 70.3 and $60.5 \%$ in high-income North America [17]. In the USA, data from the National Health and Nutrition Examination Survey (NHANES) 2005-2010 indicate a prevalence of patients with T2DM with a BMI $\geq 25 \mathrm{~kg} / \mathrm{m}^{2}$ to be $87.1 \%$ (BMI $>30 \mathrm{~kg} / \mathrm{m}^{2}: 61.2 \%$ ) [18]. In high-risk patients with T2DM, data from the Bypass angioplasty revascularization investigation in type 2 diabetes (BARI2D) trial in patients with T2DM and documented coronary artery disease showed the prevalence of obesity $\left(\mathrm{BMI} \geq 30 \mathrm{~kg} / \mathrm{m}^{2}\right)$ to be $56.4 \%$ [19]. Similarly, in the saxagliptin assessment of vascular outcomes recorded in patients with diabetes mellitus (SAVOR)-thrombolysis in myocardial infarction (TIMI) 53 study, the prevalence of obesity (BMI $\left.\geq 30 \mathrm{~kg} / \mathrm{m}^{2}\right)$ was $53 \%$ [20].

An unexpected and novel finding was an inverse correlation between diabetes duration and both BMI and WC. Recently, an inverse correlation between BMI strata, diabetes duration and age has also been reported in a pooled analysis of cross-sectional data from Spanish patients with a mean age of 63.2 years [21]. This inverse relationship could suggest less advanced disease and/or the absence of comorbidities in patients with a higher BMI, which could be related to a higher survival probability in overweight patients with T2DM or previous $\mathrm{CV}$ disease in prospective studies [22]. The negative association between disease duration and baseline BMI could, therefore, be due to survivor bias: the patients with persistently high BMI would have a greater likelihood of dying before study enrolment than those with lower BMI.

In our study, obesity was more prevalent in younger patients, women, Caucasians, "non-Hispanic or Latinos", and previous smokers when compared with corresponding groups. These observations seem to be consistent with data from the BARI-2D, a trial that featured a comparable population regarding age and BMI [19].

The higher BMI and lower WC observed in females compared with men are in line with previous findings that men have greater levels of visceral fat compared with women; thus, T2DM and CV disease may develop at a lower BMI level in men than in women [23, 24]. Also, the higher percentage of individuals of normal weight and with a healthy WC among Asian and Hispanic highrisk patients, even according to IISHMS, indicates that these individuals would have developed T2DM and have a higher CV risk at lower BMI and WC. Accordingly, the recent cross-sectional study from the UK Biobank
Participants (which included 490,288 subjects) concludes that obesity should be defined by a lower threshold in non-Caucasian than in Caucasian populations [10]. For instance, for T2DM diagnosis, a BMI of $30 \mathrm{~kg} / \mathrm{m}^{2}$ in Caucasians equates to $22 \mathrm{~kg} / \mathrm{m}^{2}$ in South Asians, and for respective WCs, $102 \mathrm{~cm}$ equates to $79 \mathrm{~cm}$ [10].

\section{Obesity and cardiometabolic risk factors}

In common with other studies, we did not find an association between weight and HbAlc level through our logistic analysis $[19,21,25]$. Conversely, we did observe an association between BMI and WC and several cardiometabolic risk factors, despite the more frequent use of statins and antihypertensives in higher BMI and WC categories. Primarily, obesity was associated with higher BP levels, higher levels of TG and low levels of HDL-C. This association was observed both across the trial population and after adjustment for potential confounding factors that are also related to obesity. These results are generally consistent with data from observational studies both in the general population and in high CV risk patients with T2DM [3, 20, 21, 25-28]. Also, a significant association of reduced eGFR with BMI (but not WC) was observed, consistent with kidney dysfunction data from the BARI-2D trial [19].

\section{Obesity and treatment intensity}

When we analysed the influence on lipid levels, the numbers of patients treated with lipid-modifying agents increased with increasing categories of BMI and WC. However, obese patients were less likely to be at the defined lipid targets, especially for HDL-C and TG levels. While the association between statin treatment and BMI is quite consistent in the medical literature [19, 26, 2931 , a greater discrepancy exists around the probability of LDL-C reaching target levels $[26,30]$.

The percentage of patients not receiving statins at baseline was $24.7 \%$. Similarly, the baseline prevalence of patients not treated with statins has been reported to be $20 \%$ in the TECOS trial (TECOS; trial evaluating CV outcomes with sitagliptin) [32]. It is also a concern that a high percentage of patients with T2DM with normal adiposity measurements are not treated with statins, despite clinical practice guidelines recommending that high-risk patients with T2DM should be treated with a statin regardless of lipid levels [33, 34]. The latter is based on data showing that statins may have cardioprotective effects extending beyond their cholesterollowering properties [35]. Similarly, patients with normal weight were less likely to be treated with antihypertensive agents compared to overweight patients, even though, similar to statins, some antihypertensive agents have shown vascular protective properties [36]. This treatment 
disequilibrium between lean and obese patients could contribute to the so-called "obesity paradox" [3].

Finally, analyses of other large randomised trials indicate that a significant proportion of patients with T2DM and coronary artery disease fail to achieve pre-specified targets for the major modifiable CV risk factors, suggesting that a combination of barriers may be preventing goals attainment [37]. Our results show that this gap is larger in obese patients with T2DM despite more intensive treatment. It is worth remembering, however, that we present data available at the time after end of the recruitment. The Standard of Care Guidelines for LEADER, developed by the Global Expert Panel, recommended statins for all patients and the following targets: $\mathrm{HbA} 1 \mathrm{c}<7.0 \%(53.0 \mathrm{mmol} / \mathrm{mol})$ (individualised depending on the patient), LDL-C $<2.6 \mathrm{mmol} / \mathrm{l}(<1.8 \mathrm{mmol} / \mathrm{l}$ in patients with previous CV disease) and $\mathrm{BP} 130 / 80 \mathrm{mmHg}$ [7]. Therefore, a cardiometabolic improvement for all participants regardless of treatment allocation could be observed during the trial.

\section{Strengths and limitations}

Strengths of our study include the large number of patients studied from a multinational and multi-ethnic population, and the context of a clinical trial where a central laboratory was used. The investigators collected data according to a standard protocol. Furthermore, taking into account not only BMI but also WC as a more accurate measure of visceral adiposity is a strength compared with previous studies. Finally, our sample allowed us to study two high-risk groups of patients: a cohort with prior CVD and a high-risk cohort but without prior CVD. Also, the multiracial population potentially makes our data more generalisable.

In interpreting our findings, however, several important limitations need to be considered. The context of a clinical trial may generate a selection bias and diminish the generalisability of the results. Thus, given the known effect of liraglutide to promote weight loss [38], overweight and obesity may be over-represented in LEADER. Also, the observation that only patients $>50$ years were enrolled in LEADER is important because some studies suggest that the relationship between $\mathrm{BMI}$ and $\mathrm{CV}$ risk could be modified by age; thus, the findings may not be generalisable to a younger population. In particular, a prospective analysis of individual records of 221,934 people indicated that the increased risk of CVD (myocardial infarction and ischaemic stroke) associated with BMI and WC was 3-4 times higher at the age of 40-59 years than at 70 years [39]. Nevertheless, post hoc analyses of the SCOUT trial that recruited patients $\geq 55$ years confirmed a relationship between weight loss and CV risk factors (such as total cholesterol) and outcomes (such as
CV mortality) [40, 41]. Furthermore, although including patients $<50$ years, studies have shown an association of obesity with suboptimal control of $\mathrm{CV}$ risk factors in diabetic patients across the mean age range of $62-65.7$ years $[2,19,21,28]$.

Another limitation to these findings is the two distinct cohorts used in this study. Female gender, for example, showed lower prevalence in the patients with prior CVD cohort than in those without prior CVD (33.5 vs. $45.4 \%$, respectively); there were also large differences in prevalence between patients with prior CVD and those without in patients aged 50-59 years (30.2 vs. $1.5 \%$, respectively), aged $60-69$ years (46.1 vs. $76.5 \%$, respectively) and those using hypertensive medication (6.8 vs. $15.7 \%$, respectively).

A further limitation is the cross-sectional nature of the study that precludes determination of causality. Furthermore, although our analyses are adjusted for multiple variables, these might have different effects in longitudinal studies. In addition, the use of single baseline values for blood pressure, cholesterol, and markers of glycaemia has been criticised because of their potential for error in measurement and within-patient fluctuation [42].

Unfortunately, detailed information about the drug classes, doses and treatment adherence were not available at the time this manuscript was developed, and therefore, the authors could not accurately evaluate the association between adiposity and treatment intensity. Finally, we did not have data on risk-taking behaviours such as unhealthy diet, sedentary lifestyle, and alcohol intake, among others, that could confound the relationship between adiposity and attainment of treatment target.

When entering the treatment phase, an important aspect is the demonstrated beneficial effects of GLP-1RA on weight. Exenatide once weekly has been, at least partly, associated with weight loss and reduced macrovascular risk in a retrospective study and a pooled analyses of eight studies $[43,44]$. A retrospective longitudinal pharmaco-epidemiological study established that the risk for composite of myocardial infarction or stroke in overweight and obese patients were not significantly higher compared to those in the normal weight group after adjusting for other factors [43]. Also, the rates $/ 1000$ person years of individual CV events in the same study were not significantly different by BMI categories (normal weight, overweight and obese) regardless of treatment groups in the study cohort [43]. Moreover, a pooled analysis from eight studies of exenatide once weekly showed that the greatest trend of improvement in $\mathrm{CV}$ risk factors was observed in patient quartiles with the greatest reductions in body weight [44]. Following the same relationship as exenatide, liraglutide has demonstrated beneficial changes in weight and body composition; indeed, 12 and 
56 week trials specifically designed to study the efficacy and safety of liraglutide for weight management have shown reductions in body weight and enhanced metabolic parameters (such as B-type ventricular natriuretic peptide, fasting lipids and urinary albumin-to-creatinine ratio) [45-47].

In summary, overweight and obesity are extremely prevalent in high-risk patients with T2DM. Furthermore, BMI and $\mathrm{WC}$ are related to major cardiometabolic risk factors, particularly BP, TG, and HDL-C. In addition, treatment intensity is higher in overweight and obese patients, compared with others; however, the rates of treatment and control of lipids and BP are remarkably suboptimal in overweight and obese individuals. As secondary data, LEADER will explore the longitudinal effects of liraglutide or placebo, when added to standard care, on CV risk factors and weight for up to 5 years of treatment.

\begin{abstract}
Abbreviations
ATPIII: adult treatment panel III criteria; BARI-2D: bypass angioplasty revascularization investigation in type 2 diabetes; BMI: body mass index; BP: blood pressure; CV: cardiovascular; CVD: cardiovascular disease; eGFR: estimated glomerular filtration rate; GLP-1RA: glucagon-like peptide-1 receptor agonist; HbA1c: glycated haemoglobin; HDL-C: high-density lipoprotein cholesterol; LDL-C: low-density lipoprotein cholesterol; IISHMS: International Joint Interim Statement for the Harmonization of the Metabolic Syndrome criteria; NHANES: national health and nutrition examination survey; OAD: oral antihyperglycaemic drug; T2DM: type 2 diabetes mellitus; TECOS: trial evaluating cardiovascular outcomes with sitagliptin; TG: triglycerides; WC: waist circumference.
\end{abstract}

\section{Authors' contributions}

All authors confirm that they meet the International Committee of Medical Journal Editors (ICJME) uniform requirements for authorship. All authors contributed to the design of the study. Data collection and trial conduct were performed by $L M$ and FMMB. Data analysis was conducted by LM, SB, FMMB, SPM and ME. All authors contributed to drafting/critically revising the article, approval of the final manuscript and sharing in the final responsibility for the content of the manuscript and the decision to submit it for publication. All authors read and approved the final manuscript.

\footnotetext{
Author details

${ }^{1}$ Endocrinology and Nutrition Department, Hospital Son Llàtzer, University Institute of Health Science Research (IUNICS-IdISPa), Universitat de les Illes Balears, Palma, Majorca, Spain. ${ }^{2}$ Divisions of Endocrinology and Metabolism, Li Ka Shing Knowledge Institute and Keenan Research Centre for Biomedical Science, St. Michael's Hospital, University of Toronto, Toronto, ON, Canada. ${ }^{3}$ Endocrinology and Nutrition Department, Hospital Clínic, Institut d'Investigacions Biomèdiques August Pi i Sunyer (IDIBAPS), University of Barcelona, Barcelona, Spain. ${ }^{4}$ Institute of Life Science, Swansea University, Swansea, UK. ${ }^{5}$ Institute of Cardiovascular and Medical Science, BHF Glasgow Cardiovascular Research Centre, University of Glasgow, Glasgow, UK. ${ }^{6}$ Mossakowski Medical Research Centre, Polish Academy of Sciences and Central Clinical Hospital MSW, Warsaw, Poland. ${ }^{7}$ Diabetes Unit, Internal Medicine Division, Hadassah Hebrew University Hospital, Jerusalem, Israel. ${ }^{8}$ Department of Internal Medicine, Division of Endocrinology, Inciralti, Izmir, Turkey. ${ }^{9}$ Praxis für Prävention und Therapie, Kardio Metabolischen Instituts, Villingen-Schwenningen, Germany. ${ }^{10}$ Department of Endocrinology, Diabetology, and Metabolism, Faculty of Medicine, Antwerp University Hospital, Edegem, Antwerp, Belgium. ${ }^{11}$ Novo Nordisk, Copenhagen, Denmark. ${ }^{12}$ Division of Cardiology, University of Texas Southwestern Medical Center, Dallas, TX, USA. ${ }^{13}$ Department of Endocrinology, Metabolism and Diabetes, Karolinska University Hospital, Stockholm, Sweden
}

\section{Acknowledgements}

Funding for the LEADER Trial was provided by Novo Nordisk. The authors gratefully acknowledge the assistance of P. Sanchis, PhD, from University Institute of Health Science Research (IUNICS)-Universitat de les Illes Balears, in writing the manuscript. The authors would like to thank David Dynnes Ørsted, Liraglutide Diabetes, Global Medical Affairs, Novo Nordisk A/S and Henrik Wachmann, Department of Biostatistics, Novo Nordisk A/S from Novo Nordisk for coordination in the preparation of this paper and statistical analysis, respectively. We also thank Watermeadow Medical (supported by Novo Nordisk) for providing editorial support.

\section{Competing interests}

LM has served on advisory panels for Janssen and Novo Nordisk; has received research support from Sanofi-Aventis; has been a member of a speakers' bureau for Abbott, AstraZeneca, Eli Lilly, MSD, Novo Nordisk, and Sanofi-Aventis; and has been a researcher in clinical trials with Boehringer Ingelheim, GSK, Novo Nordisk, and Sanofi-Aventis. LAL has been a member of advisory panels for AstraZeneca, Boehringer Ingelheim, Eli Lilly, GlaxoSmithKline, Janssen, Merck, Novo Nordisk, Sanofi-Aventis, Servier, and Takeda; has received research support from AstraZeneca, Boehringer Ingelheim, Eli Lilly, GlaxoSmithKline, Janssen, Merck, Novo Nordisk, SanofiAventis, and Servier; and has served on a speakers' bureau for AstraZeneca, Boehringer Ingelheim, Eli Lilly, Janssen, Merck, Novo Nordisk, Sanofi-Aventis, and Takeda. JV declares no conflicts of interest. SB has been a member of advisory panels for AstraZeneca, Bristol-Myers Squibb, Boehringer Ingelheim, Janssen, Lilly, MSD, Novo Nordisk, and Sanofi-Aventis; and is a board member for Glycosmedia. JP has received consultancy fees, presented lectures been an advisor and member of study committee with Novo Nordisk; has been an advisor for Alere, Lilly, MSD, and Sanofi-Aventis; received clinical trial support in from JDRF; received non-financial clinical trial support in from Merck and Itamar Medical; received meeting support from and was an advisor to AstraZeneca; and was a member of an endpoint committee for Quintiles. EF has been a member of advisory panels for AstraZeneca/ Bristol-Meyers Squibb, Bioton, Boehringer Ingelheim, Johnson and Johnson, Novartis, Novo Nordisk; and has been a part of a speakers' bureau for AstraZeneca/Bristol-Meyers Squibb, Bioton, Boehringer Ingelheim, Merck, Novo Nordisk A/S, and Servier. IR has been a member of advisory panels for AstraZeneca/Bristol-Meyers Squibb, Eli Lilly, LabStyle Innovations, Medscape LLC, MSD, Novo Nordisk, Orgenesis, Sanofi-Aventis, and SmartZyme Innovation; has been a consultant for AstraZeneca/Bristol-Meyers Squibb, FuturRx, Gili Medical, Insuline Medical, and Kamada; has been a part of a speakers' bureau for AstraZeneca/Bristol-Meyers Squibb, Eli Lilly and Company, Johnson and Johnson, MSD, Novartis, Novo Nordisk, Sanofi-Aventis, and Teva; and is a shareholder for Glucome, Insuline Medical, LabStyle Innovations, Orgenesis, and SmartZyme Innovation. AC has been an advisory panel and board member for AstraZeneca, Eli Lilly, MSD, Novo Nordisk and Sanofi-Aventis; has received research support from AstraZeneca, Boehringer Ingelheim, MSD, Novartis, and Novo Nordisk; and has been a speakers' bureau member for Astra Zeneca, Eli Lilly, MSD, Novartis, Novo Nordisk, and Sanofi. SJ has been on an advisory panel, a consultant, received research support or been a part of a speakers' bureau for Abbott, AstraZeneca, Bayer, Bristol-Myers Squibb, Boehringer Ingelheim, Daiichi-Sankyo, Essex, GSK, Janssen, Johnson and Johnson, Lilly, Merck, MSD, Novo Nordisk, Novartis, Pfizer, Roche, Sanofi-Aventis, Solvay, Takeda and Viatris. LVG has been on an advisory panel for AstraZeneca, Boehringer Ingelheim, Bristol-Myers Squibb, Eli Lilly, Janssen, MSD, Novartis, Novo Nordisk, and Sanofi; and has been a part of a speakers' bureau AstraZeneca, Boehringer Ingelheim, Bristol-Myers Squibb, Eli Lilly, Janssen, MSD, Novartis, Novo Nordisk, and Sanofi-Aventis. FMMB is a full-time employee and stockholder of Novo Nordisk A/S. SPM has been a consultant for Novo Nordisk; and has received research support from AstraZeneca, Bristol-Myers Squibb, Novo Nordisk, Terumo, and The Medicines Company. ME has been a member of advisory boards for Amgen, Aegerion, Chiesi, MSD, and Sanofi-Aventis; has received research support from Amgen, MSD, and Sanofi-Aventis; and has been part of a speakers' bureau for Amgen, Fresenius, and MSD. The authors declare that they have no competing interests.

Received: 3 November 2015 Accepted: 22 January 2016

Published online: 10 February 2016 


\section{References}

1. Bastien M, Poirier P, Lemieux I, Despres JP. Overview of epidemiology and contribution of obesity to cardiovascular disease. Prog Cardiovasc Dis. 2014:56:369-81.

2. Bhan V, Yan RT, Leiter LA, Fitchett DH, Langer A, Lonn E, et al. Guidelines oriented approach in lipid lowering (GOALL) registry and vascular protection (VP) registry investigators. Relation between obesity and the attainment of optimal blood pressure and lipid targets in high vascular risk outpatients. Am J Cardiol. 2010;106:1270-6.

3. Goyal A, Nimmakayala KR, Zonszein J. Is there a paradox in obesity? Cardiol Rev. 2014;22:163-70.

4. Leenders M, Verdijk LB, van der Hoeven L, Adam JJ, van Kranenburg J, Nilwik R, et al. Patients with type 2 diabetes show a greater decline in muscle mass, muscle strength, and functional capacity with aging. J Am Med Dir Assoc. 2013;14:585-92.

5. Lavie CJ, Milani RV, Ventura HO. Obesity and cardiovascular disease: risk factor, paradox, and impact of weight loss. J Am Coll Cardiol. 2009;53:1925-32.

6. Look AHEAD Research Group, Wing RR, Bolin P, Brancati FL, Bray GA, Clark $\mathrm{JM}$, et al. Cardiovascular effects of intensive lifestyle intervention in type 2 diabetes. N Engl J Med. 2013;369:145-54.

7. Marso SP, Poulter NR, Nissen SE, Nauck MA, Zinman B, Daniels GH, et al. Design of the liraglutide effect and action in diabetes: evaluation of cardiovascular outcome results (LEADER) trial. Am Heart J. 2013;166:823-30.

8. Sumner AE. The relationship of body fat to metabolic disease: influence of sex and ethnicity. Gend Med. 2008;5:361-71.

9. Goh LG, Dhaliwal SS, Welborn TA, Lee AH, Della PR. Anthropometric measurements of general and central obesity and the prediction of cardiovascular disease risk in women: a cross-sectional study. BMJ Open. 2014;4:e004138.

10. Ntuk UE, Gill JM, Mackay DF, Sattar N, Pell JP. Ethnic-specific obesity cutoffs for diabetes risk: cross-sectional study of 490,288 UK biobank participants. Diabetes Care. 2014;37:2500-7.

11. Jensen MD, Ryan DH, Apovian CM, Ard JD, Comuzzie AG, Donato KA, et al. 2013 AHA/ACC/TOS guideline for the management of overweight and obesity in adults: a report of the American college of cardiology/American heart Association task force on practice guidelines and the obesity society. Circulation. 2014;129:S102-38.

12. Expert Panel on Detection. Evaluation and treatment of high blood cholesterol in adults. executive summary of the third report of the national cholesterol education program (NCEP) expert panel on detection, evaluation, and treatment of high blood cholesterol in adults (adult treatment panel III). JAMA. 2001;285:2486-97.

13. Alberti KG, Eckel RH, Grundy SM, Zimmet PZ, Cleeman II, Donato KA, et al. Harmonizing the metabolic syndrome: a joint interim statement of the International diabetes federation task force on epidemiology and prevention; national heart, lung, and blood institute; American Heart Association; World Heart Federation; International Atherosclerosis Society; and International Association for the Study of Obesity. Circulation. 2009;120:1640-5

14. Tillin T, Sattar N, Godsland IF, Hughes AD, Chaturvedi N, Forouhi NG. Ethnicity-specific obesity cut-points in the development of Type 2 diabetes - a prospective study including three ethnic groups in the United Kingdom. Diabet Med. 2015;32:226-34.

15. American Diabetes Association. Standards of medical care in diabetes-2014. Diabetes Care. 2014;37:S14-80.

16. Baxi S, Lakin J, Lyles CR, Berkowitz S, Horton C, Sarkar U. Points for improvement: performance measurement for glycemic control in diabetes patients in a safety-net population. Jt Comm J Qual Patient Saf. 2013;39:109-13.

17. Ng M, Fleming T, Robinson M, Thomson B, Graetz N, Margono C, et al. Global, regional, and national prevalence of overweight and obesity in children and adults during 1980-2013: a systematic analysis for the global burden of disease study 2013. Lancet. 2014;384:766-81.

18. Selvin E, Parrinello CM, Sacks DB, Coresh J. Trends in prevalence and control of diabetes in the United States, 1988-1994 and 1999-2010. Ann Intern Med. 2014;160:517-25.

19. Albu JB, Lu J, Mooradian AD, Krone RJ, Nesto RW, Porter MH, et al. Relationships of obesity and fat distribution with atherothrombotic risk factors: baseline results from the Bypass Angioplasty Revascularization
Investigation 2 Diabetes (BARI 2D) trial. Obesity (Silver Spring) 2010;18:1046-54.

20. Scirica BM, Bhatt DL, Braunwald E, Steg PG, Davidson J, Hirshberg B, et al. Saxagliptin and cardiovascular outcomes in patients with type 2 diabetes mellitus. N Engl J Med. 2013;369:1317-26.

21. Vázquez LA, Rodríguez Á, Salvador J, Ascaso JF, Petto H, Reviriego J. Relationships between obesity, glycemic control, and cardiovascular risk factors: a pooled analysis of cross-sectional data from Spanish patients with type 2 diabetes in the preinsulin stage. BMC Cardiovasc Disord. 2014;14:153.

22. McEwen LN, Karter AJ, Waitzfelder BE, Crosson JC, Marrero DG, Mangione $\mathrm{CM}$, et al. Predictors of mortality over 8 years in type 2 diabetic patients: translating research into action for diabetes (TRIAD). Diabetes Care. 2012;35:1301-9.

23. Logue J, Walker JJ, Colhoun HM, Leese GP, Lindsay RS, McKnight JA, et al. Do men develop type 2 diabetes at lower body mass indices than women? Diabetologia. 2011;54:3003-6.

24. Collier A, Ghosh S, Hair M, Waugh N. Gender differences and patterns of cardiovascular risk factors in Type 1 and Type 2 diabetes: a populationbased analysis from a Scottish region. Diabet Med. 2015;32:42-6.

25. Molenaar EA, Hwang SJ, Vasan RS, Grobbee DE, Meigs JB, D'Agostino RB $\mathrm{Sr}$, et al. Burden and rates of treatment and control of cardiovascular disease risk factors in obesity: the Framingham Heart Study. Diabetes Care. 2008;31:1367-72.

26. Swinburn BA, Sacks G, Hall KD, McPherson K, Finegood DT, Moodie ML et al. The global obesity pandemic: shaped by global drivers and local environments. Lancet. 2011;378:804-14.

27. Chopra I, Kamal KM, Candrilli SD, Kanyongo G. Association between obesity and therapeutic goal attainment in patients with concomitant hypertension and dyslipidemia. Postgrad Med. 2014;126:66-77.

28. Li P, Chen K, Nie Y, Guo LL, Wang HB, Wang SS, et al. Association of obesity with glucose, blood pressure, and lipid goals attainment in patients with concomitant diabetes and hypertension. Curr Med Res Opin 2015:31:1623-31.

29. Daousi C, Casson IF, Gill GV, MacFarlane IA, Wilding JP, Pinkney JH. Prevalence of obesity in type 2 diabetes in secondary care: association with cardiovascular risk factors. Postgrad Med J. 2006;82:280-4.

30. Rückert IM, Maier W, Mielck A, Schipf S, Völzke H, Kluttig A, et al. Personal attributes that influence the adequate management of hypertension and dyslipidemia in patients with type 2 diabetes. Results from the DIABCORE cooperation. Cardiovasc Diabetol. 2012;11:120.

31. Jones NR, Fischbacher CM, Guthrie B, Leese G, Lindsay RS, McKnight JA, et al. Factors associated with statin treatment for the primary prevention of cardiovascular disease in people within 2 years following diagnosis of diabetes in Scotland, 2006-2008. Diabet Med. 2014;31:640-6.

32. Bethel MA, Green JB, Milton J, Tajar A, Engel SS, Califf RM, et al. Regional, age and sex differences in baseline characteristics of patients enrolled in the trial evaluating cardiovascular outcomes with Sitagliptin (TECOS). Diabetes Obes Metab. 2015;17:395-402.

33. Stone NJ, Robinson JG, Lichtenstein AH, Bairey Merz CN, Blum CB, Eckel $\mathrm{RH}$, et al. ACC/AHA guideline on the treatment of blood cholesterol to reduce atherosclerotic cardiovascular risk in adults: a report of the American college of cardiology/American Heart Association task force on practice guidelines. J Am Coll Cardiol. 2013;2014(63):2889-934.

34. American Diabetes Association. Cardiovascular disease and risk management. Sec. 8. In standards of medical care in diabetes 2015. Diabetes Care. 2015;38:S49-57.

35. Ludman A, Venugopal V, Yellon DM, Hausenloy DJ. Statins and cardioprotection-more than just lipid lowering? Pharmacol Ther. 2009;122:30-43.

36. Guenette L, Breton MC, Hamdi H, Gregoire JP, Moisan J. Important treatment gaps in vascular protection for the elderly after type 2 diabetes therapy initiation. Can J Cardiol. 2013;29:1593-8.

37. Farkouh ME, Boden WE, Bittner $\mathrm{V}$, Muratov V, Hartigan $\mathrm{P}$, Ogdie $M$, et al Risk factor control for coronary artery disease secondary prevention in large randomized trials. J Am Coll Cardiol. 2013;61:1607-15.

38. Niswender K, Pi-Sunyer X, Buse J, Jensen KH, Toft AD, Russell-Jones D, et al. Weight change with liraglutide and comparator therapies: an analysis of seven phase 3 trials from the liraglutide diabetes development programme. Diabetes Obes Metab. 2013;15:42-54.

39. The Emerging Risk Factors Collaboration. Separate and combined associations of body-mass index and abdominal adiposity with cardiovascular 
disease: collaborative analysis of 58 prospective studies. Lancet. 2011;377(9784):1085-95.

40. Weeke P, Andersson C, Fosbøl EL, Brendorp B, Køber L, Sharma AM, et al. The weight lowering effect of sibutramine and its impact on serum lipids in cardiovascular high risk patients with and without type 2 diabetes mellitus - an analysis from the SCOUT lead-in period. BMC Endocr Disord. 2010;10:3.

41. Caterson ID, Finer N, Coutinho W, van Gaal LF, Maggioni AP, Torp-Pedersen $C$, et al. Maintained intentional weight loss reduces cardiovascular outcomes: results from the sibutramine cardiovascular OUTcomes (SCOUT) trial. Diabetes Obes Metab. 2012;14:523-30.

42. Wormser D, Wood AM, Di Angelantonio E, Thompson SG, Danesh J. Emerging risk factors collaboration. Metabolic mediators of body-mass index and cardiovascular risk. Lancet. 2014;383:2042-3.

43. Paul SK, Klein K, Maggs D, Best JH. The association of the treatment with glucagon-like peptide-1 receptor agonist exenatide or insulin with cardiovascular outcomes in patients with type 2 diabetes: a retrospective observational study. Cardiovasc Diabetol. 2015;14:10.

44. Blonde L, Pencek R, MacConell L. Association among weight change, glycemic control, and markers of cardiovascular risk with exenatide once weekly: a pooled analysis of patients with type 2 diabetes. Cardiovasc Diabetol. 2015;14:12.

45. Li CJ, Yu Q, Yu P, Yu TL, Zhang QM, Lu S, et al. Changes in liraglutideinduced body composition are related to modifications in plasma cardiac natriuretic peptides levels in obese type 2 diabetic patients. Cardiovasc Diabetol. 2014;13:36.

46. Pi-Sunyer X, Astrup A, Fujioka K, Greenway F, Halpern A, Krempf M, et al. A randomized, controlled trial of $3.0 \mathrm{mg}$ of liraglutide in weight management. N Engl J Med. 2015;373:11-22.

47. Davies MJ, Bergenstal R, Bode B, Kushner RF, Lewin A, Skjøth TV, et al. Efficacy of liraglutide for weight loss among patients with type 2 diabetes: the SCALE diabetes randomized clinical trial. JAMA. 2015;314:687-99.

\section{Submit your next manuscript to BioMed Central and we will help you at every step:}

- We accept pre-submission inquiries

- Our selector tool helps you to find the most relevant journal

- We provide round the clock customer support

- Convenient online submission

- Thorough peer review

- Inclusion in PubMed and all major indexing services

- Maximum visibility for your research

Submit your manuscript at www.biomedcentral.com/submit
() Biomed Central 